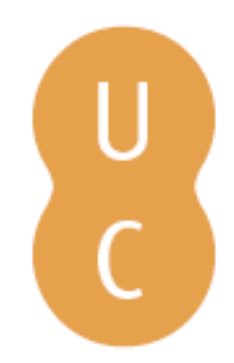

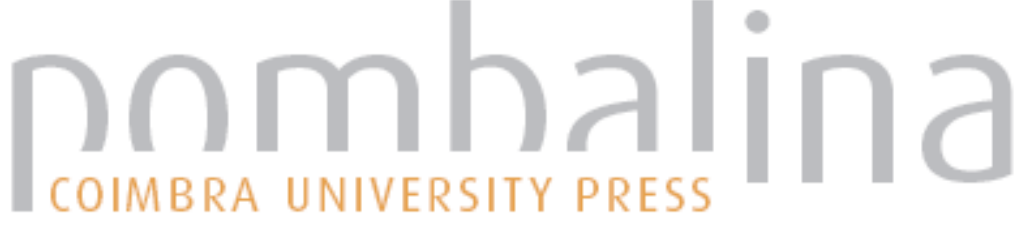

\section{Republicanismo na Constituição de 1891}

Autor(es): $\quad$ Lewandowski, Enrique Ricardo

Publicado por: Imprensa da Universidade de Coimbra

URL

persistente: URI:http://hdl.handle.net/10316.2/30857

DOI: $\quad$ DOI:http://dx.doi.org/10.14195/978-989-26-0497-8_4

Accessed : $\quad$ 26-Apr-2023 02:26:57

A navegação consulta e descarregamento dos títulos inseridos nas Bibliotecas Digitais UC Digitalis, UC Pombalina e UC Impactum, pressupõem a aceitação plena e sem reservas dos Termos e Condições de Uso destas Bibliotecas Digitais, disponíveis em https://digitalis.uc.pt/pt-pt/termos.

Conforme exposto nos referidos Termos e Condições de Uso, o descarregamento de títulos de acesso restrito requer uma licença válida de autorização devendo o utilizador aceder ao(s) documento(s) a partir de um endereço de IP da instituição detentora da supramencionada licença.

Ao utilizador é apenas permitido o descarregamento para uso pessoal, pelo que o emprego do(s) título(s) descarregado(s) para outro fim, designadamente comercial, carece de autorização do respetivo autor ou editor da obra.

Na medida em que todas as obras da UC Digitalis se encontram protegidas pelo Código do Direito de Autor e Direitos Conexos e demais legislação aplicável, toda a cópia, parcial ou total, deste documento, nos casos em que é legalmente admitida, deverá conter ou fazer-se acompanhar por este aviso.

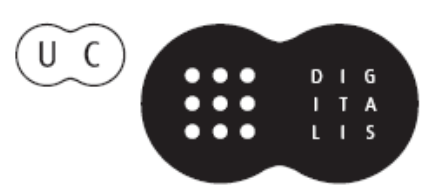


Armando Malheiro da Silva

Maria Luiza Tucci Carneiro

Stefano Salmi

Coordenação

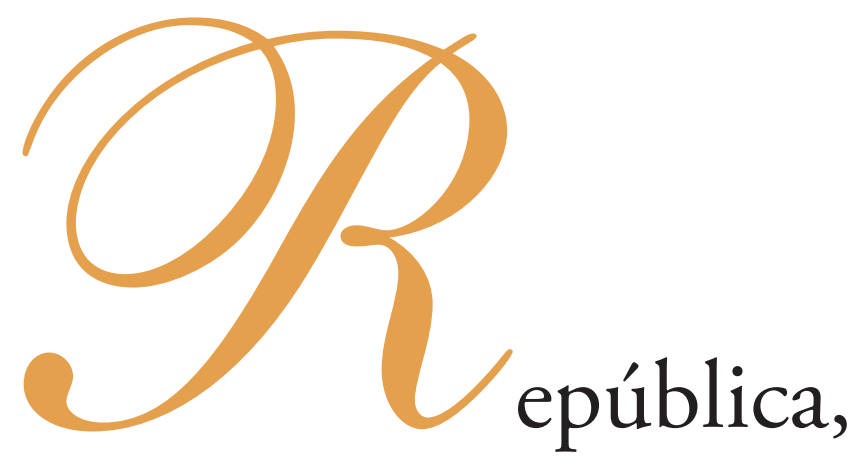

Republicanismo

e Republicanos

Brasil • Portugal • Itália 


\section{Enrique Ricardo Lewandowski}

\section{REPUBLICANISMO NA CONSTITUIÇÃO DE 1891}

\section{Princípio estruturante}

Os constituintes de 1988, não por acaso, adotaram a forma de governo escolhida pelo povo 1891, em substituição à monarquia, estabelecendo, logo no $\operatorname{artigo} 1^{\circ}$ da Carta Magna, que o Brasil é uma República. Tratou-se de uma escolha deliberada e plena de conseqüências, ratificada pela cidadania no plebiscito realizado cinco anos após a sua promulgação, nos termos do art. $2^{\circ}$ do Ato das Disposições Constitucionais Transitórias.

A se levar em conta a importância da topologia para a hermenêutica constitucional, não há como deixar de reconhecer que, quando os constituintes adotaram forma republicana de governo, na verdade estavam definindo um dos princípios estruturantes de nossa Lei maior. Com efeito, o princípio republicano, ao lado dos princípios federativo e democrático, configuram, no dizer da doutrina, núcleos essenciais da Constituição ${ }^{106}$, visto que lhe garantem determinada identidade e estrutura.

Para melhor compreender o significado do princípio republicano, que passou a integrar todas as constituições brasileiras editadas a partir de 1891, convém estudá-lo à luz de uma perspectiva histórica, de maneira a identificar suas características essenciais, moldadas por uma elaboração doutrinária e uma prática política multisseculares.

\footnotetext{
${ }^{106}$ CANOTILHO, José Joaquim Gomes - Direito Constitucional. Coimbra: Almedina, 1992, p. 349.
} 


\section{Res publica, res populi}

De Roma antiga, onde República identificava algo que a pertencia a todos (res publica) ou ao povo (res populi), até os dias atuais, o conceito sofreu uma longa evolução, embora tenha conservado, em linhas gerais, os fundamentos axiológicos que lhe deram origem.

Instituída pelos romanos, no início do século v a. C., a partir da superação da realeza, a república encerra a idéia de coisa comum, de um bem pertencente à coletividade, correspondendo em linhas gerais à antiga noção grega de politeia, regime em que os cidadãos participavam ativamente da gestão da polis. Opõe-se às demais formas de governo, a exemplo da monarquia, na qual se realça o conceito de mando, ou seja, de archia, derivado archein, que significa comandar, chefiar ${ }^{107}$.

Cícero definiu-a como a "coisa do povo, considerada tal, não todos os homens de qualquer modo congregados, mas a reunião que tem seu fundamento no consentimento jurídico e na utilidade comum"108. A República, portanto, para o pensador romano, não era uma mera multidão de pessoas reunidas sob uma determinada autoridade, mas uma comunidade de interesses organizada sob a égide da lei.

Maquiavel, embora paradoxalmente tenha defendido o exercício de um poder sem limites por parte do príncipe, retomou, séculos depois, o conceito original de República, com base nos clássicos da antigüidade ${ }^{109}$. Na verdade, não apenas ele, mas também os demais republicanos do cinquecento, para os quais a idéia de liberdade, balizada pela lei comum, constituía um dos eixos em torno qual girava o "humanismo cívico" que praticavam"10.

Nem sempre, porém, ao longo da História, o termo República teve o mesmo significado. Na Idade Média, as palavras res publica, imperium, regnum e civitas eram empregadas indistintamente para designar aquilo que hoje se entende por

\footnotetext{
${ }^{107}$ Cfr. Verbete "República". In BOBBIO, Norberto [et al]. - Dicionário de Política. Brasília, Editora Universidade de Brasília, 1991.

${ }^{108}$ De República. I, 25.

${ }^{109}$ Ver especialmente Il Principe e Discorsi sopra la prima deca di Tito Livio.

${ }^{110}$ BIGNOTO, Newton - Maquiavel Repubblicano. São Paulo: Loyola, 1991, p. 57.
} 
Estado (stato), expressão que só tornou-se corrente a partir do século XVI ${ }^{111}$. Mesmo depois de findo o medievo, não se atribuiu à palavra qualquer significado especial, lembrando-se que Bodin associou-a ao exercício de um poder absoluto e perpétuo, que denominou de "soberano"

\section{Soberania popular e representação política}

A concepção romana de República foi resgatada, no século XVIII, por Rousseau, para quem ela correspondia a um "Estado regido pelas leis, qualquer que seja a sua forma de administração", em que "o interesse público governa e a coisa pública é alguma coisa"113. O pensador genebrino, ademais, desenvolveu a idéia de que as leis procedem da vontade geral, derivada do contrato social, a qual não se subordina a nenhuma condição (Quidquid populi placuit legis habet vigorem) $)^{114}$.

Mas a maior contribuição de Rousseau para o conceito moderno de República foi, sem dúvida, a afirmação da igualdade essencial dos cidadãos, visto que o contrato, sobre o qual se assenta o Estado, coloca todos sob idênticas condições, fazendo com que tenham os mesmos direitos ${ }^{115}$. Também a liberdade, para o autor, decorre do pacto fundamental, na medida em que somente aos que o integram compete editar normas de convivência social ${ }^{116}$.

Coerentemente com essas idéias, Rousseau concluía que os cidadãos para fazer as leis exprimem sua vontade de forma direta, sem qualquer intermediação, rejeitando, assim, a possibilidade de representação, razão pela qual reduzia os deputados a meros comissários do povo, "que não estão aptos a decidir definitivamente"117.

${ }^{111}$ JELLINEK, Gerog - Teoria General del Estado. Buenos Aires: Albatros, 1973, p. 99.

${ }^{112}$ Les six lives de la république, I, 8.

${ }^{113}$ Du Contrat Social, II, 6.

${ }^{114}$ DE JOUVENEL, Bertrand - De la souveraineté: a la recherche du bien politique. Paris: Génin, 1955 , p. 216

${ }^{115}$ Rousseau, op. cit., loc. cit.

${ }^{116}$ Idem, ibidem.

${ }^{117}$ Idem, III, 6 
Kant, seu contemporâneo, embora entendendo também que a res publica latius sic dicta constitui "uma forma de união criada pelo interesse comum de todos os que vivem sob o império da lei”"18, divergia da concepção rousseaniana da participação direta dos cidadãos no governo, explicando que uma verdadeira República "é e não pode deixar de ser um sistema representativo, no qual os direitos do povo são custodiados por deputados que representam a vontade unificada dos cidadãos"119.

No Novo Mundo a tese segundo a qual a representação popular configura o cerne de um governo republicano dominou o pensamento político. Madison, cujos escritos, ao lado dos de Hamilton e Jay, contribuíram decisivamente para moldar o arcabouço institucional dos Estados Unidos, assinalava que uma República consiste num "governo que deriva os seus poderes direta ou indiretamente do povo, e é administrado por pessoas que se mantém nos respectivos cargos, por um período limitado, ao arbítrio daquele, ou enquanto bem servirem”, associando também à noção o princípio da separação dos poderes desenvolvido por Montesquieu como instrumento de contenção do arbítrio dos agentes estatais ${ }^{120}$.

Eletividade e responsabilidade

Numa República os governantes, escolhidos pelo povo, são responsáveis diante dele pela gestão dos negócios públicos. Não exercem o poder por direito próprio, constituindo meros mandatários dos cidadãos. Nessa forma de governo, impera a soberania popular, que encontra expressão por meio de representantes eleitos, distinguindo-se dos regimes despóticos nos quais o povo não tem qualquer ação sobre os governantes, ao mesmo tempo em que se aparta das formas diretas de participação popular, em que os cidadãos governam por si mesmos ${ }^{121}$. A legitimidade dos representantes do povo radica em eleições que têm como base o sufrágio geral, igual, direto e secreto, que caracteriza, segundo alguns,

\footnotetext{
${ }^{118}$ Die Methaphysik der Sitten, II, § 43.

${ }^{119}$ Idem, II, § 52 .

120 The Federalist, 39 e 47.

${ }^{121}$ MAHLBERG, Carré de - Contribution a la Theorie Génerale de L'État. Tomo II. Paris: Sirey,
} 1922, p. 202. 
a própria ratio essendi da República ${ }^{122}$. Para dar-lhe concreção, impõe-se estender o direito de votar a todos os cidadãos, com exclusão apenas daqueles que não preencham os requisitos da capacidade, vedada qualquer restrição baseada em sexo, raça, rendimento, instrução, ideologia etc.

Exige-se, por outro lado, que todos os votos tenham a mesma eficácia jurídica, ou seja, o mesmo valor de resultado. O voto há-de ter também imediatidade, isto é, deve defluir diretamente da vontade do eleitor, sem intermediação de quem quer que seja e livre de pressões de qualquer espécie. Além disso, o voto pressupõe não apenas a pessoalidade de seu exercício, como também a ausência de qualquer possibilidade de identificação do eleitor. Finalmente o voto precisa ser renovado periodicamente, de modo a assegurar a alternância dos representantes no poder.

\section{Direitos e deveres}

Na República romana, os cidadãos de pleno direito (optimo jure), em oposição aos estrangeiros (peregrini), eram detentores de direitos políticos (jura politica), que compreendiam o voto nos comícios, a elegibilidade para as magistraturas, o acesso ao sacerdócio e faculdade de apelar quando processados ${ }^{123}$. Também gozavam de direitos civis (jura privata), que incluíam a propriedade, o casamento entre iguais e a possibilidade de demandar na Justiça ${ }^{124}$. Em contrapartida, sujeitavam-se a obrigações (munera), com destaque para o dever de participar do recenseamento (census), de servir no exército (militia) e de pagar imposto (tributum) ${ }^{125}$.

A idéia moderna de República, a partir da Declaração dos Direitos do Homem e do Cidadão, aprovada pela Assembléia francesa 1789, encontra-se indissoluvelmente ligada à idéia de que os indivíduos são titulares de direitos em face do Estado, em especial à vida, à liberdade, à propriedade e à participação política. Isso porque, com as revoluções liberais-burguesas, a relação entre governantes e

${ }^{122}$ CANOTILHO, José Joaquim Gomes - Direito Constitucional e Teoria da Constituição. $3^{\mathrm{a}}$ ed. Coimbra: Almedina, 1999, p. 159.

${ }^{123}$ LANÇON, Bertrand - O Estado Romano: Catorze séculos de modelos políticos. Sinora: Europa-América, 2003, p. 26.

${ }^{124}$ Ibidem.

${ }^{125}$ Ibidem. 
governados passou a ser entrevista mais ex parte populi, do ponto de vista dos cidadãos, do que ex parte principis, da perspectiva dos detentores do poder ${ }^{126}$.

Apenas mais tarde, a partir da Revolução Industrial e das lutas operárias desencadeadas desde meados do século XIX, surgiram os chamados "direitos sociais", tais como o direito ao trabalho, à saúde e à educação, que passaram a integrar as constituições promulgadas a partir de então, ao lado dos direitos civis e políticos, que já faziam parte das cartas magnas surgidas em conseqüência da derrocada do absolutismo monárquico.

\section{Sentimento republicano no Brasil}

O ideal republicano no Brasil inspirou, ainda que de forma difusa e inarticulada, grande parte das revoltas e insurreições deflagradas desde os fins do século XviII e no decorrer da primeira parte da centúria seguinte, que pretendiam instituir governos independentes e republicanos. Mas o ambiente histórico somente tornou-se propício à derrubada do regime monárquico depois da segunda metade do século XIX, quando, em meio à crise política e econômica gerada pelo fim da escravidão, "um bando de idéias novas agita o País e dá-lhe novas diretrizes"127.

Com efeito, nessa quadra histórica, o naturalismo, o evolucionismo e o positivismo passaram a influenciar as convicções da elite pensante, sobretudo dos profissionais liberais e da oficialidade militar, ensejando uma tomada de posição crítica, impregnada de laicismo, com relação às instituições políticas então vigentes. As novas idéias foram entusiasticamente difundidas, sobretudo nas academias militares e nas escolas de engenharia e de direito.

Os jovens engenheiros militares e civis adotaram a filosofia positiva de Augusto Comte, enquanto os bachareis em direito abraçaram a doutrina evolucionista de Herbert Spencer ou de Ernesto Haeckel ${ }^{128}$. Por toda a parte cresciam os ataques

\footnotetext{
${ }^{126}$ BOBBIO, Norberto; VIROLI, Maurizio - Diálogo em torno da República: os grandes temas da política e da cidadania. Rio de Janeiro: Campus, 2002, p. 52

${ }^{127}$ COSTA, Cruz - Pequena História da República. $3^{\text {a }}$ ed. São Paulo: Civilização Brasileira, 1974, p. 25.

${ }^{128}$ SANTOS, Carlos Maximiliano Pereira dos - Comentários à Constituição Brasileira de 1891. Brasília: Senado Federal, 2005, Ed. Fac.similar, p. 86, nota 61.
} 
à Monarquia e às suas tradições, em especial ao "poder moderador", prerrogativa constitucional que permitia ao Imperador interferir nos demais poderes, tida como a "tirania da coroa"129.

Deposto D. Pedro II, em 15 de Novembro de 1889, por um golpe militar liderado pelo Marechal Deodoro de Fonseca, a imprensa, interpretando o sentimento dos insurgentes e seus adeptos, no mesmo dia registrava que o Brasil, com o fim do ancien régime, ingressou numa nova fase, "passando a regime francamente democrático com todas as conseqüências da liberdade"130.

\section{Um comtismo mitigado}

Benjamin Constant foi um dos principais difusores do comtismo no exército, valendo-se de sua condição de professor da Escola Militar. E como o levante republicano originou-se preponderantemente nos quartéis, a filosofia de Augusto Comte exerceu considerável influência nas lideranças políticas, ao menos nos dias que se seguiram à derrubada do regime monárquico.

Mas o comtismo que prevaleceu no Brasil foi uma versão mitigada da tradição dogmática e autoritária do pensador francês, caracterizando-se como uma corrente heterodoxa, vinculada mais ao positivismo cientificista predominante na época do que aos aspectos político-religiosos da doutrina original, de caráter antidemocrático $^{131}$. Por esse motivo não vingaram integralmente as idéias dos "cadetes filósofos", que pretendiam instituir no Brasil uma "ditadura científica", capitaneada pelo Executivo ${ }^{132}$.

Nesse sentido, são bastante reveladores do estado de espírito dos militares, sobretudo da oficialidade mais jovem, os trechos de dois discursos publicados no Diário Oficial de 14 de Dezembro de 1889, dirigidos a Demétrio Ribeiro, Ministro do Governo Provisório. Num deles, Nelson de Almeida, em nome da Marinha,

\footnotetext{
${ }^{129}$ Ibidem, p. 27.

${ }^{130}$ Apud Cruz Costa, op. cit., p. 43

${ }^{131}$ VITA, Luis Washington - Antologia do Pensamento Social e Político no Brasil. São Paulo: Grijalbo, 1968, p. 227.

${ }^{132}$ Apud BALEEIRO, Aliomar - Constituições Brasileiras: 1891. vol. II. Brasília: Senado Federal e Ministério da Ciência e Tecnologia, 1999, pp. 31 a 33.
} 
afirmava que, "para termos uma República estável, feliz e próspera, é necessário que o governo seja ditatorial e não parlamentar"; noutro Tasso Fragoso, falando pelo exército, recordava "o pensamento do egrégio filósofo (Augusto Comte), quando sintetizou como qualidades do verdadeiro governo - força e responsabilidade"133.

O que prevaleceu foi um comtismo abrandado, que, deixando de lado os arroubos autoritários de alguns seguidores mais extremados da doutrina, logrou imprimir a sua marca no novo regime. São de sua inspiração, por exemplo, o desenho e os dizeres da nova bandeira do País. Isso porque, de acordo com Augusto Comte, as bandeiras nacionais poderiam ser mantidas na primeira fase de transição da humanidade para o positivismo, imaginado por ele como uma religião de cunho racional. Assim, os novos detentores do poder quando conceberam o pavilhão republicano conservaram o fundo verde, o losango amarelo e o círculo azul do pendão imperial, substituindo os seus emblemas pela divisa "Ordem e Progresso" e o conjunto de estrelas - uma para cada província — que retratava o céu do Rio de Janeiro no dia 15 de Novembro ${ }^{134}$.

O Governo Provisório, instalado após a derrubada da Monarquia, ademais, baixou decretos que estabeleceram a liberdade de culto, a separação da Igreja e do Estado e a secularização dos cemitérios ${ }^{135}$. Também instituiu o casamento civil, sem o divórcio a vínculo, cominando a pena de prisão aos sacerdotes que ministrassem o sacramento do matrimônio a pessoas ainda não casadas civilmente. Além disso, num paroxismo anticlerical, expulsou a Companhia de Jesus e negou aos padres seculares o direito de voto ${ }^{136}$.

No plano institucional, aboliu o Conselho de Estado, dissolveu a Câmara dos Deputados e acabou com a vitaliciedade no Senado, passando o País a denominar-se oficialmente República dos Estados Unidos do Brasil, como expressão do regime político e da estrutura federal que os novos dirigentes adotaram ${ }^{137}$.

\footnotetext{
${ }^{133}$ LEAL, Aurelino de Araújo - História Constitucional do Brasil. Edição fac-similar. Brasília: Senado Federal, Conselho Editorial, 2002, pp. 217/218.

${ }^{134}$ MORAES FILHO, V. Evaristo de (org.) - Auguste Comte: sociologia. São Paulo: Ática, 1978, esp. pp. $149-151$.

135 SANTOS, Carlos Maximiliano Pereira dos - op. cit., p. 86.

${ }^{136}$ Ibidem, pp. 86 e 87.

${ }^{137}$ Ibidem, p. 87.
} 


\section{A Constituinte republicana}

A redação da nova Constituição foi confiada a uma comissão integrada por Saldanha Marinho, Américo Brasiliense, Antonio Luiz dos Santos Werneck, Francisco Rangel Pestana e José Pedreira de Magalhães Castro, cujos trabalhos, iniciados em Dezembro de 1889, resultaram em um anteprojeto oferecido ao Congresso Constituinte, depois de revisto por Ruy Barbosa, cuja tônica foi a adoção do modelo político-institucional dos Estados Unidos da América, sobretudo quanto ao presidencialismo e ao federalismo ${ }^{138}$, já vigentes na Argentina desde 1853.

Eleita em Novembro de 1990, a Constituinte, integrada por homens de classe média e das profissões liberais, advogados, médicos, engenheiros civis e militares, funcionários públicos e oficiais da marinha e do exército, após cerca de três meses de debates e votações, sob a presidência de Prudente José de Moraes Barros, promulgou a nova Carta Magna, em 24 de Fevereiro de 1891, pouco modificando o anteprojeto que lhe foi submetido pelo Governo Provisório.

Os mentores do novo regime não alimentavam maiores dúvidas sobre o seu significado. Rui Barbosa, um de seus principais artífices, tomando emprestadas as palavras do constitucionalista norte-americano Campell Black, definia a República, tout court, como um governo "do povo, para o povo e pelo povo", que se apoia na igualdade política dos homens ${ }^{139}$.

Os especialistas contemporâneos não se afastam muito desse conceito quando assinalam que "república é o regime político em que os exercentes das funções políticas (executivas e legislativas) representam o povo e decidem em seu nome, fazendo-o com responsabilidade, eletivamente e mediante mandatos renováveis periodicamente" ${ }^{140}$. As características essenciais dessa forma de governo são, pois, a eletividade, a temporariedade e a responsabilidade dos governantes.

É interessante reparar que a Monarquia, como forma de governo oposta à República, ostenta características diametralmente contrárias, quais sejam, a vitaliciedade, a hereditariedade e a irresponsabilidade ${ }^{141}$. Em outras palavras,

\footnotetext{
${ }^{138}$ SANTOS, Carlos Maximiliano Pereira dos - op. cit., p. 88.

${ }^{139}$ PIRES, Homero (org.) - Rui Barbosa: Teoria Política. Rio de Janeiro: Jackson Editores, 1950, p.48.

${ }^{140}$ ATALIBA, Geraldo - República e Constituição. São Paulo: Revista dos Tribunais, 1985, p. IX.

${ }^{141}$ DALLARI, Dalmo de Abreu - Elementos de Teoria Geral do Estado. 16ª ed. São Paulo: Saraiva, 1991, p. 191.
} 
o monarca governa "enquanto viver ou enquanto tiver condições de governar", procedendo-se à sua escolha "pela simples verificação da linha de sucessão", não devendo "explicações ao povo ou a qualquer órgão sobre os motivos pelos quais adotou certa orientação política"142.

\section{Republicanismo na Constituição de 1891}

$\mathrm{O}$ art. $72^{\circ}$ da Constituição de 1891 assegurava aos brasileiros e estrangeiros residentes no País, "a inviolabilidade dos direitos à liberdade, à segurança individual e à propriedade", ao mesmo tempo em que estabelecia, nos parágrafos subseqüentes, o princípio da legalidade - segundo o qual ninguém é obrigado a fazer ou deixar de fazer algo senão em virtude de lei — e o da igualdade de todos os cidadãos. Com relação à isonomia, o $\S 2^{\circ}$ do referido artigo consignava enfaticamente o seguinte: "A República não admite privilégio de nascimento, desconhece foros de nobreza, e extingue as ordens honoríficas existentes e todas as suas prerrogativas e regalias, bem como os títulos nobiliárquicos e de conselho".

Sob a égide da Constituição de 1824, por outro lado, a pessoa do Imperador era "inviolável e sagrada", em contraste com as cartas republicanas que a ela se seguiram, nas quais, sem exceção, previu-se que o Chefe de Estado pode perder o mandato pela prática de crime de responsabilidade, sem prejuízo de outras sanções. Essa pena, também no ordenamento legal ora vigente, não é privativa do supremo mandatário da Nação, aplicando-se a todos os representantes eleitos, que são afastados das respectivas funções, assim como os demais servidores estatais, consonância com os postulados da accountability e da responsivenes, caso pratiquem atos incompatíveis com o múnus público que lhes é cometido.

Nessa linha, o art. $53^{\circ}$ da primeira Carta republicana, estabelecia que o Presidente da República será "submetido a processo e julgamento, depois que a Câmara julgar procedente a acusação, perante o Supremo Tribunal Federal, nos crimes comuns, e, nos de responsabilidade, perante o Senado". Já o art. 82, previa que os "funcionários públicos são estritamente responsáveis pelos abusos e

\footnotetext{
${ }^{142}$ Ibidem, loc. cit.
} 
omissões em que incorrerem no exercício de seus cargos, assim como pela indulgência, ou negligência em não responsabilizarem efetivamente seus subalternos."

A Constituição de 1891 adotou o regime representativo, fazendo expressa menção a ele logo no art. $1^{\circ}$, consignando, mais abaixo, no art. $15^{\circ}$, que os poderes Legislativo, Executivo e Judiciário são "órgãos da soberania nacional”. Os artigos $16, \S 2^{\circ}$, e $17, \S \S 2^{\circ}$ e $3^{\circ}, 28,30,41, \S 3^{\circ}$, e 43 , por sua vez, abrigavam a regra da eletividade dos agentes políticos, estabelecendo ainda a temporariedade dos mandatos, tanto dos parlamentares como do Presidente da República. Tais disposições foram expressamente estendidas aos Estados-membros da Federação, por força do art. $63^{\circ}$.

O sistema representativo, como se sabe, além de eleições livres, pressupõe ainda a existência de mecanismos que estabeleçam o predomínio da vontade da maioria, com a garantia de que as minorias encontrem expressão no plano político. Para isso, além do pluripartidarismo, é preciso assegurar também a liberdade de opinião, de reunião e de associação, além de outras franquias pertinentes.

Coerentemente com esses postulados, a nossa primeira Carta republicana, no art. 28 , assegurava, de forma expressa, a "representação da minoria". Essa disposição foi considerada pelo jurista e constituinte João Barbalho, "uma das mais notáveis disposições da Constituição", concebida para "suprimir a tirania das maiorias parlamentares, assegurando a livre expansão e influência de todas as aspirações legítimas que surjam no país e tendam ao em público"143.

Além de outras garantias, ela também assegurava, no art. $72, \S 8^{\circ}$, o direito de associação e de reunião, liberdades que, no Império, era reguladas por lei ordinária. O $\S 12^{\circ}$ daquele dispositivo garantia também a livre manifestação do pensamento "pela imprensa e pela tribuna, sem dependência de censura".

\section{Movimentos reformistas}

Apesar dos inegáveis avanços propiciados pela primeira Constituição republicana, mal foi ela promulgada, logo surgiram os que, diante dos primeiros

\footnotetext{
${ }^{143}$ CAVALCANTI, João Barbalho Uchôa - Constituição Federal Brasileira 1891 comentada. Edição fac-similar. Brasília: Senado Federal, 2002, p. 83. 38.
} 
percalços, passaram a defender a sua revisão: alguns pretendiam apenas retocá-la para aperfeiçoar certos aspectos; outros buscavam uma reforma mais radical de maneira a restaurar o regime parlamentarista vigente no Império e reduzir a autonomia dos Estados $^{144}$.

É que, desde os primórdios da República, duas correntes de opinião digladiavam-se entre si $^{145}$. De um lado situavam-se os militares, que defendiam um Estado forte e unitário e um Executivo dominante. Influenciados pelas idéias positivistas, consideravam-se cidadãos especiais, cuja formação e disciplina os credenciava a liderar o desenvolvimento racional do País, mediante um planejamento levado a cabo por técnicos que promoveriam o progresso e ampliariam o conhecimento científico.

De outra banda, localizavam-se os republicanos paulistas, que defendiam o aprofundamento federalismo, visto que se sentiam espoliados pelo crescente centralismo que se implantou no Brasil desde o fim do período regencial, sobretudo no tocante à redistribuição, para outras regiões, da receita tributária gerada em São Paulo.

As elites paulistas, ademais, em que pese o centralismo político que caracterizou o período monárquico, lograram concretizar com êxito políticas locais próprias, em especial o apoio à bem-sucedida imigração estrangeira, desenvolvida a partir de 1846, majoritariamente direcionada para a província. Os republicanos paulistas, além disso, também defendiam as teses liberais clássicas da divisão e equilíbrio entre os poderes Legislativo, Executivo e Judiciário, da necessidade de eleições para todos os cargos políticos e de uma atitude abstencionista do Estado com relação à economia.

A primeira reforma da Constituição, todavia, somente foi levada a efeito em 1926, já nas vésperas da Revolução de 30, sem que nada de substancial fosse alterado. Interessantemente, os temas agitados pelos reformistas até hoje são objeto de acirradas polêmicas. Com efeito, as várias constituições editadas a partir de então não lograram resolver a questão do desequilíbrio entre os entes federativos, da hipertrofia do Executivo diante dos demais poderes,

\footnotetext{
${ }^{144}$ CALDEIRA, V. Jorge - Viagem pela História do Brasil. São Paulo: Companhia das Letras, 1997, pp. 233-235.

${ }^{145}$ Ibidem, loc.cit.
} 
da concentração de competências e rendas no âmbito da União e da atuação errática do Estado no âmbito da economia.

\section{O legado republicano}

A República no Brasil, como é notório, não resultou de uma revolução popular, mas foi produto das elites, representadas pela aristocracia rural e pela burguesia urbana, infensas a uma mudança social mais profunda. Por isso mesmo, os constituintes de 1891, mantiveram-se dentro certos limites, sobretudo no tocante à participação popular.

O direito de sufrágio, por exemplo, ficou restrito a uma pequena minoria, visto que, segundo o art. $70^{\circ}$, apenas "os cidadãos maiores de 21 anos, que se alistarem na forma da lei”, eram eleitores. Dessa condição estavam excluídos os mendigos, os analfabetos, as praças de pré e os religiosos. Mesmo o que se chamava de "voto secreto" nada mais era do que o voto fechado, ou seja, entregava-se ao eleitor uma cédula fechada numa sobrecarta, que seria depositada na urna.

As mulheres também não podiam participar das eleições. Prevaleceu na Constituinte a idéia segundo a qual "a missão da mulher é mais doméstica do que pública, mais moral do que política” ${ }^{146}$. O pretexto para negar-lhes o direito ao sufrágio era que a mulher "normal e típica, não é a que vai ao foro, nem à praça publica, nem às assembléias políticas defender direitos da coletividade, mas a que fica no lar doméstico, exercendo as virtudes feminis, base da tranqüilidade da família, e por conseqüência da felicidade social”. ${ }^{147}$ As brasileiras somente consquistaram os direitos políticos após a Revolução de 30.

Sem embargo dessas e de outras limitações, a Constituição de 1891 teve méritos inegáveis. Instituiu o regime republicano e, no seu bojo, a democracia representativa, bem como o sistema de governo presidencialista e a forma federal de Estado, que sobreviveram com altos e baixos até os dias de hoje. Desprezando um parlamentarismo que jamais representou a contento a opinião pública, dado

\footnotetext{
${ }^{146}$ Trecho de discurso proferido pelo deputado Pedro Americo na sessão de 27 de Janeiro de 1891, apud, CAVALCANTI, João Barbalho Uchôa - op. cit., p. 291.

${ }^{147}$ Idem, loc. cit.
} 
o artificialismo que caracterizava os partidos políticos no regime monárquico, os constituintes adotaram o presidencialismo, que vingou definitivamente, até por ser mais consentâneo com o personalismo que caracteriza as instituições políticas latino-americanas.

Já o princípio da indissolubilidade da federação, aliado ao mecanismo da intervenção do governo central nos Estados-membros, abrigado em todas as constituições, contribuiu para manter íntegro, sem embargo de veleidades secessionistas episódicas, um país de dimensões continentais, que a República herdou sem fissuras da Monarquia ${ }^{148}$.

Pode-se dizer que, atualmente, o princípio republicano, entre nós, representa a viga mestra do "sentimento constitucional" (Verfassungsgefüll) a que se refere a doutrina alemã, ou seja, de um estado de espírito coletivo que, "transcendendo todos os antagonismos e tensões existentes, político-partidárias, econômico-sociais, religiosas ou de outro tipo, integra os detentores e destinatários do poder num marco de uma ordem comunitária obrigatória”149. Com efeito, os valores republicanos básicos, em especial da igualdade de todos perante a lei, da soberania popular e da responsabilidade dos agentes públicos, hoje são imunes a qualquer retrocesso no ideário político dos brasileiros.

\section{Bibliografia}

ATAliBA, Geraldo - República e Constituição. São Paulo: Revista dos Tribunais, 1985.

BALEEIRO, Aliomar - Constituições Brasileiras: 1891. Brasília, Senado Federal e Ministério da Ciência e Tecnologia, 1999

BIGNOTTO, Newton - Maquiavel Republicano. São Paulo: Loyola, 1991.

BOBBIO, Norberto [et al] - Verbete "República". Dicionário de Política. Brasília: Editora Universidade de Brasília, 1991.

BOBBIO, Norberto; VIROLI, Maurizio - Diálogo em torno da República: os grandes temas da política e da cidadania. Rio de Janeiro: Campus, 2002.

BODIN, Jean - Les six lives de la republique.

${ }^{148}$ A revolução constitucionalista de 1932, apesar de a tradição histórica atribuir-lhe um móvel exclusivamente republicano, não deixou de apresentar um componente secessionista, sobretudo por revelar um certo saudosismo pela perda da hegemonia política da elite paulista diante da ascenção de novas forças sociais no cenário nacional.

${ }^{149}$ LOEWENSTEIN, Kart - Teoría de la Constitución. 2a ed. Barcelona: Editorial Ariel, 1976, p. 200. 
CALDERA, Jorge - Viagem pela História do Brasil. São Paulo: Companhia das Letras, 1997, pp. $233-235$.

CANOTILHO, José Joaquim Gomes - Direito Constitucional. Coimbra: Almedina, 1992.

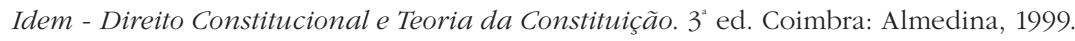

CAVALCANTI, João Barbalho - Constituição Federal Basileira 1891 comentada. Edição fac-similar. Brasília: Senado Federal, 2002.

CICERO, Marco Tulio - De República.

COSTA, Cruz, Pequena História da República - $3^{a}$ ed. São Paulo: Civilização Brasileira, 1974.

DALLARI, Dalmo de Abreu - Elementos de Teoria Geral do Estado, 16 a ed. São Paulo: Saraiva, 1991.

JAY, John; HAMILTON, Alexander; MADISON, James - The Federalist.

JELLINEK, Georg - Teoria General del Estado. Buenos Aires: Albatros, 1973.

JOUVENEL, Bertrand de - De la souveraineté: a la recherche du bien politique. Paris: Génin, 1955.

KANT, Immanuel - Die Methaphysik der Sitten.

LANÇON, Bertrand - O Estado Romano: Catorze séculos de modelos políticos. Sintra: Europa-América, 2003.

LEAL, Aurelino de Araújo - História Constitucional do Brasil. Edição fac-similar. Brasília, Senado Federal: Conselho Editorial, 2002.

LOEWENSTEIN, Kart - Teoría de la Constitución. 2a . ed. Barcelona: Editorial Ariel, 1976.

MAQUIAVEL, Nicolau - Il Principe e pagine de altre opere. Padova: Cedam, 1940.

MAHLBERG, Carré de - Contribution a la Theorie Génerale de L'État. Paris: Sirey, 1922.

MORAES FILHO, Evaristo (org.) - Auguste Comte: sociologia. São Paulo: Ática, 1978.

PIRES, Homero (org.) - Rui Barbosa: Teoria Política. Rio de Janeiro: Jackson Editores, 1950.

ROUSSEAU, Jean Jacques - Du Contrat Social.

SANTOS, Carlos Maximiliano Pereira dos - Comentários à Constituição Brasileira de 1891. Edição fac-similar. Brasília, Senado Federal, 2005.

VITA, Luis Washington - Antologia do Pensamento Social e Político no Brasil. São Paulo: Grijalbo, 1968. 